\title{
Knowledge of cardiopulmonary resuscitation of clinicians at a South African tertiary hospital
}

Botha L, MBChB, MMed Emergency Medicine Consultant and Lecturer, Division of Emergency Medicine, Department of Family Medicine, Faculty of Health Sciences, University of Pretoria Geyser MM, BSc, MBChB, BScHons(Pharm), DipPec, MPracMed, FCEM(SA), MSc(Clin Epi) Head of Kalafong Hospital Emergency Centre; Senior Lecturer Department of Family Medicine and Emergency Medicine, Faculty of Health Sciences, University of Pretoria Engelbrecht A, MBChB, FCEM(SA), MMed, DipPec, DA, DTM\&H Professor and Head, Division of Emergency Medicine, Department of Family Medicine, Faculty of Health Sciences, University of Pretoria Correspondence to: Liesl Botha, e-mail: lieslbotha@vodamail.co.za Keywords: resuscitation knowledge, clinicians, education, South Africa

\section{Abstract}

Objectives: The objectives of this study were to assess clinicians' knowledge about evaluating possible cardiac arrest patients and recognising cardiac arrest, to assess clinicians' knowledge about appropriate decisions and actions during cardiopulmonary resuscitation (CPR), and to determine which advanced life support courses had been undertaken and whether they were still valid.

Design: This was a descriptive, cross-sectional survey.

Setting and subjects: The subjects were doctors who worked in clinical disciplines at a South African tertiary hospital. Using convenience sampling, doctors from each clinical discipline were invited to participate. Those who consented were included, until a sample of 100 was obtained.

Outcome measures: A self-administered, closed-ended questionnaire that was based on the course content of the American Heart Association (AHA) Basic Life Support (BLS) course was used. The minimum score of $84 \%$, benchmarked against the AHA BLS course, was used to define adequate knowledge.

Results: One hundred doctors participated. None of the participants showed adequate knowledge. The mean total score was $35.1 \%$ (95\% Cl: 31.7 ; 38.6). The mean adult CPR score was $40.6 \%$ (95\% Cl: $37.4 ; 45.6)$. The mean paediatric CPR score was $36.6 \%$ (95\% Cl: $37.0 ; 41.6)$.

Conclusion: The participants' knowledge of resuscitation was poor. This raises considerable concern about the effectiveness of the CPR that is performed. This study highlights the need for adequate training of clinicians in the skill of resuscitation and the importance of developing appropriate CPR training programmes that are accessible, innovative and inexpensive.

(P) Peer reviewed. (Submitted: 2011-11-28. Accepted: 2012-02-12.) ๑ SAAFP

S Afr Fam Pract 2012;54(5):447-454

\section{Introduction}

Sudden cardiac arrest is a catastrophic medical emergency that may occur at any time in the hospital or pre-hospital setting. Cardiopulmonary resuscitation (CPR) and basic life support (BLS) are important life-saving, first-aid skills. $\mathrm{CPR}$ is an emergency procedure that is performed in an effort to manually preserve intact brain function until further measures can be taken to restore spontaneous blood circulation and breathing in the person who is experiencing the cardiac arrest. It involves chest compressions and artificial respiration. ${ }^{1}$ BLS refers to the maintenance of airway patency and the support of breathing and circulation without the use of equipment, other than a protective device. ${ }^{2}$ Therefore, knowledge of CPR is crucial to the improvement of patient survival. It is especially important that medical staff have adequate knowledge of CPR as they may be confronted with a patient in cardiac arrest during their duties.

\section{Epidemiology of sudden death}

Sudden cardiac death is a major health problem in most countries. Sudden unexpected death is defined as death within 24 hours of symptom onset in a previously functional individual. ${ }^{3}$ Cardiac arrest is defined as "cessation of cardiac mechanical activity, confirmed by the absence of detectable pulse, unresponsiveness, and apnoea, or agonal, gasping respirations". ${ }^{4}$

Sudden death accounts for one third of all nontraumatic deaths. Most occur outside the hospital. Seventy-five per cent of sudden nontraumatic deaths are attributed to cardiovascular disease. The remaining $25 \%$ are attributed to noncardiac causes. The incidence of sudden death is about $0.26 \% .^{5}$ 
Coronary artery disease is the most common pathological condition that is found in patients who die suddenly. Other cardiac causes include cardiomyopathy and specific structural abnormalities, such as valvular heart disease. Noncardiac causes include respiratory failure, circulatory obstruction and hypovolaemia, metabolic and toxic causes. The most common metabolic cause of cardiac arrest is hyperkalaemia. $^{5}$

\section{Management of cardiac arrest}

Theonly clinically feasible interventions that haveconsistently been shown to improve survival from cardiac arrest are early CPR, early defibrillation, CPR before defibrillation after prolonged arrest, and prolonged hypothermia induced after the return of spontaneous circulation. ${ }^{6}$

\section{History of cardiopulmonary resuscitation}

Techniques were developed in the $18^{\text {th }}$ century to keep people alive. The Society for the Recovery of Drowned Persons in Amsterdam was the first organised effort to respond to sudden death and claimed that people were saved by their recommendations. ${ }^{7}$ Notices were read in churches that described the assistance that would need to be given to drowned, strangled and frozen people, as well as to those who were overcome by noxious gases. These recommendations were probably the first example of mass medical training. Rescue societies of the $18^{\text {th }}$ century were the precursors of today's emergency medical services (EMS). Over the next 150 years, scientists and charlatans advocated hundreds of resuscitation techniques.

In 1954, James Elam was the first to demonstrate experimentally that CPR was a sound technique, and together with $\mathrm{Dr}$ Peter Safar, they demonstrated its superiority to previous methods. Safar wrote the book $A B C$ of resuscitation ${ }^{8}$ in 1957 and collaborated with Norwegian toy maker, Åsmund Laerdal, to create "Resusci Anne," the CPR training mannequin. Safar combined mouth-to-mouth breathing and closed-chest cardiac massage to become the BLS method of CPR. ${ }^{8}$

The first successful electrical reversal of ventricular fibrillation (VF) by externally applied paddles was reported by Zoll in $1956 .^{9}$

Modern elements of resuscitation for sudden cardiac arrest are CPR (which consists of mouth-to-mouth ventilation and chest compression), defibrillation and EMS (the means to bring these techniques to the patient quickly).

\section{Effectiveness of cardiopulmonary resuscitation}

CPR does not "bring anyone back". Effective CPR helps by circulating oxygenated blood. Therefore, tissue death is delayed and the brief window of opportunity for successful resuscitation without permanent brain damage extended. Usually, advanced life support (ALS), especially defibrillation, is needed to restore a viable rhythm. The arrival of the automated external defibrillator meant that defibrillation now forms part of BLS. ${ }^{6}$

Many studies have examined CPR in specific communities. While they have shown varying rates of success, all are consistent in showing the benefits of early CPR. Early CPR and defibrillation that are instituted within the first 3-5 minutes after collapse, in conjunction with early advanced care, can result in higher (greater than 50\%) long-term survival rates for witnessed VF. ${ }^{10}$

When cardiac arrest is witnessed in hospital, there are a higher proportion of patients who achieve return of spontaneous circulation (ROSC) and who ultimately survive to be discharged from hospital, than those who experience unwitnessed in-hospital cardiac arrest (Table I). The reasons for this may include medical staff being unable to primarily address the cause of the cardiac arrest, or may be as a result of the patient's pre-existing co-morbidities and poor physiological reserve. ${ }^{11}$ Bystander resuscitation has a far lower percentage of ROSC and survival than inhospital resuscitation. ${ }^{12}$ Table I clearly demonstrates the considerable impact early that defibrillation has on both the ROSC and survival of patients. ${ }^{10}$

Table I: The return of spontaneous circulation and survival percentages in the different types of arrest

\begin{tabular}{|c|c|c|}
\hline Type of arrest & ROSC & Survival \\
\hline Witnessed in-hospital cardiac arrest ${ }^{11}$ & $48 \%$ & $22 \%$ \\
\hline Unwitnessed in-hospital cardiac arrest ${ }^{11}$ & $21 \%$ & $1 \%$ \\
\hline Bystander cardiocerebral resuscitation ${ }^{12}$ & $40 \%$ & $6 \%$ \\
\hline Bystander cardiopulmonary resuscitation ${ }^{12}$ & $40 \%$ & $4 \%$ \\
\hline No bystander CPR (ambulance CPR) ${ }^{12}$ & $15 \%$ & $2 \%$ \\
\hline Defibrillation within 3-5 minutes ${ }^{10}$ & $74 \%$ & $30 \%$ \\
\hline
\end{tabular}

CPR: cardiopulmonary resuscitation, ROSC: return of spontaneous circulation

\section{Cardiopulmonary resuscitation guidelines}

The International Liaison Committee on Resuscitation (ILCOR) was formed in 1992 to provide an opportunity for the major organisations in resuscitation to work together on CPR and emergency cardiovascular care protocols. ILCOR comprises the American Heart Association (AHA), the European Resuscitation Council, the Heart and Stroke Foundation of Canada, the Australian and New Zealand Committee on Resuscitation, the Resuscitation Councils of Southern Africa, the Resuscitation Councils of Asia and the Inter-American Heart Foundation. In 2005, CPR guidelines were published by ILCOR. ${ }^{13}$

Some workers downplayed the importance of artificial respirations and focused on chest compressions only. A study by the University of Arizona claimed a $300 \%$ 
greater success rate over standard CPR. ${ }^{14}$ In March 2007, a Japanese study presented strong evidence that compressing the chest, not mouth-to-mouth ventilation, was the key to helping someone recover from cardiac arrest. ${ }^{15}$ On 30 March 2008, the AHA broke away from the ILCOR position and stated that compression-only CPR works as well as, and sometimes better than, traditional CPR. ${ }^{16}$ In 2010, ILCOR published new guidelines incorporating this. ${ }^{17}$ The next scheduled revision of the guidelines is in 2015 .

\section{Challenges with cardiopulmonary resuscitation}

The majority of people do not survive cardiac arrest. Few people receive CPR and fewer receive high-quality CPR. ${ }^{18}$ High-quality CPR is defined as compressions at a rate of at least 100 compressions per minute ("push hard, push fast"), allowing full chest recoil after each compression, minimising interruptions in chest compressions and avoiding hyperventilation. ${ }^{6}$ Populations who are trained in CPR are essential for survival of the patient with cardiac arrest. ${ }^{6}$ Medical literature reveals that most out-of-hospital cardiopulmonary arrest victims do not receive any bystander CPR and healthcare providers deliver suboptimal BLS and ALS during actual cardiopulmonary arrests, both in and out of the hospital. ${ }^{6,18}$

The discrepancies between the current state of evidencebased resuscitation guidelines and the quality of delivered BLS and ALS represent a missed opportunity and provide a significant target for optimising patient outcomes through improved educational effectiveness.

\section{Cardiopulmonary resuscitation knowledge and skill}

It is assumed that doctors are competent in CPR, but studies have indicated that there is poor retention of both knowledge and skills in this area. ${ }^{19-22}$ Ragavan et al demonstrated that the level of knowledge and skills in basic resuscitation among medical practitioners in public hospitals in Northern province were poor and that resuscitation experience without training was not found to be beneficial. ${ }^{22}$

Although accurate knowledge of guidelines is associated with increased odds of correct performance of aspects of CPR, overall performance remains poor. ${ }^{23}$

\section{Cardiopulmonary resuscitation training}

According to the literature, retention of CPR skills is poor, regardless of the teaching method. Einspruch et al demonstrated that generally, self-trained subjects demonstrated CPR skill retention equivalent to that of AHA Heartsaver-trained subjects. ${ }^{24}$ Although that may be true, the medical community strives to advance CPR education by investigating methods to attain and retain skills and make CPR education readily accessible to all.
Nearly all CPR instruction takes place in organised classes that are led by a specially trained instructor. The premise of having instructors supervise trainee skill practice and assess mastery is that the instructors can improve trainee skill levels with feedback and can assure that trainees perform the CPR skills competently. Braslow's study of AHA instructors showed that instructors lack sufficient knowledge to teach the classes, that they deviate in many ways from recommended teaching practices and that they may teach important skills incorrectly. ${ }^{25}$ Kaye et al, in an in-depth study of AHA and American Red Cross training classes, raised serious doubts about the role played by instructors in supporting and evaluating trainee skill mastery. ${ }^{26}$ Because the presumed role of the instructor in providing quality control has been challenged, another area to explore would be models for CPR instruction that do not use a trained instructor, such as self-training, automated training and peer training. ${ }^{27}$

The literature documents elements that are important to incorporate into future training programmes. These include reducing course duration ${ }^{28}$ and distributing practice sessions over time, using modular self-training courses, and maximising time spent in deliberate practice of CPR and other resuscitation skills on manikins. ${ }^{27,28}$ Other important elements include providing targeted feedback, ${ }^{27}$ constructing mock scenarios ${ }^{29}$ that match the learner's usual clinical practice and integrating simulation ${ }^{18}$ that is compatible with specified educational objectives.

Resuscitation experience without feedback increases confidence, not skill. ${ }^{22,30}$ Experience is no substitute for training. Castle et al highlighted that a structured resuscitation training programme resulted in a noticeable improvement in BLS skills. ${ }^{31}$ Waisman et al found that the Paediatric Advanced Life Support (PALS) course significantly increased immediate short-term knowledge. They gave their support to the use of PALS as an educational tool. ${ }^{32}$ Lowenstein et al concluded that long-term survival after inpatient cardiac arrest was significantly increased (from 1323\%) with Advanced Cardiac Life Support trained staff. ${ }^{33}$

The evidence that knowledge and skills deteriorate if no revision courses are taken was reiterated in a study of 31 physicians in Canada whose resuscitation skills were measured six months after initial training. By that time, their skills and knowledge had deteriorated to pre-training levels. ${ }^{34}$

The optimal timing of retraining is an important issue to resolve because healthcare providers and laypeople often find it difficult to schedule initial CPR training, much less timely and efficient refresher courses.

A survey of doctors with ALS training indicated that $73 \%$ found CPR to be stressful. It was statistically proven that six-monthly training and updates were associated with less stress and increased confidence. ${ }^{35}$ Berden et al also 
concluded that reinstruction at six-monthly intervals was sufficient to maintain adequate skills. ${ }^{36}$ Ragavan et al recommended mandatory formal training in resuscitation at undergraduate and postgraduate level, with refresher courses held every two years. ${ }^{22}$ This is also the AHA's recommendation. ${ }^{10}$

\section{Problem statement}

Anecdotal reports indicate that doctors working in clinical disciplines have inadequate knowledge of CPR. This has not been proven by research.

\section{Motivation for this study}

No such study has been conducted in a South African tertiary hospital setting. Currently, it is possible to specialise at the University of Pretoria in most clinical disciplines without adequate CPR knowledge. ${ }^{37}$ The only exceptions are the specialities of Emergency Medicine and General Surgery. Surgery candidates are expected to have a valid Advanced Trauma Life Support certificate. ${ }^{37}$ The demonstration of inadequate CPR knowledge in our tertiary hospital could be used as a motivation for a change in training programmes and to develop alternative CPR training programmes that might be less expensive and more accessible than available existing courses for clinicians.

Ultimately, better-trained rescuers mean more lives saved.

\section{Method}

A descriptive, cross-sectional study design was used. Medical doctors working in clinical disciplines at a South African tertiary hospital were chosen as the study population. Convenience sampling was carried out.

Inclusion criteria were doctors (interns, medical officers and registrars) working in Anaesthesiology, Emergency Medicine, Internal Medicine, Neurology, Obstetrics and Gynaecology, Orthopaedics, Paediatrics, General Surgery, Neurosurgery, Thoracic Surgery and Urology.

Exclusion criteria were medical students, consultants and doctors who refused to give their consent or did not attend departmental meetings.

The proportion of clinicians with adequate knowledge was estimated to accuracy within $10 \%$ from a sample of at least 97 participants, with $95 \%$ confidence.

Each clinical discipline's meeting was attended once during the period from September 2010 to January 2011. Every doctor who was eligible for the study was invited to participate and those who were willing were included until a sample of 100 was obtained.

\section{Measurement}

A self-administered, close-ended questionnaire was used. Section A included demographic details (data information sheet) and Section B covered general resuscitation (evaluation and identification of a patient requiring assistance and decisions and actions taken), as well as adult CPR (decisions and actions) and paediatric CPR (decisions and actions).

The questionnaire was derived from a standard reference, namely the AHA guidelines for CPR and emergency cardiac care. ${ }^{1,6}$ The questions were based on the course content of the AHA BLS course and were validated by an experienced AHA BLS instructor. A minimum score of $84 \%$ defined adequate knowledge (as outlined in the AHA BLS courses).

\section{Ethical considerations}

The study was approved by the University of Pretoria's research ethics committee and permission was obtained from the hospital CEO. All the requirements of this committee were fulfilled, including those with regard to informed consent (participant information leaflet), anonymity and confidentiality.

All participant information was confidential. Only the researcher and the statistician had access to the raw data. Upon completion of the study, the data were stored in a research store facility with controlled access within the Department of Family Medicine.

\section{Data analysis}

Descriptive statistics were used on the data and are presented as graphs and tables. The proportion of clinicians with adequate knowledge was expressed as a percentage and a $95 \%$ confidence interval (Cl). Each item (question) in the questionnaire was summarised as a proportion or percentage and this information was utilised to address aspects of CPR.

\section{Results}

Of the 100 doctors who participated, 50 were male and 50 female (incidentally), with a mean age of 30.3 years $(95 \% \mathrm{Cl}$ : 29.6-31.1). Figure 1 shows the year in which the participants received their pregraduate qualification. The majority were senior registrars (41). Fifteen were medical officers (see Figure 2).

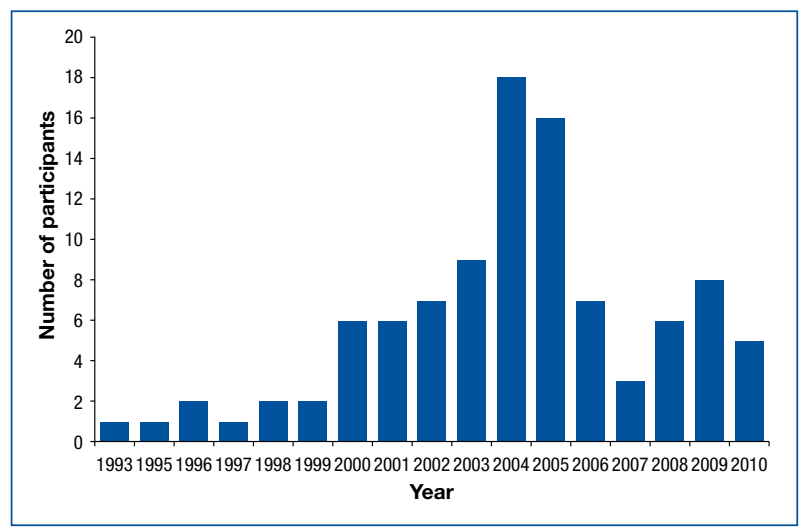

Figure 1: Participants' year of pregraduate qualification 


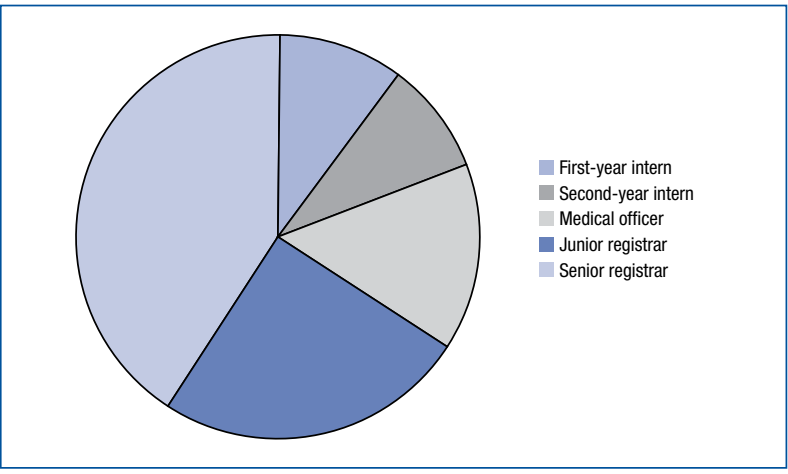

Figure 2: Proportion of participants according to capacity

Table II: Participating number of doctors in each discipline

\begin{tabular}{|l|c|}
\hline Clinical discipline & Number \\
\hline Anaesthesia & 9 \\
\hline Emergency medicine & 12 \\
\hline Internal medicine & 12 \\
\hline Neurology & 7 \\
\hline Paediatrics & 9 \\
\hline Surgery & 32 \\
\hline Cardiothoracic surgery & 3 \\
\hline General surgery & 13 \\
\hline Neurosurgery & 2 \\
\hline Obstetrics and Gynaecology & 4 \\
\hline Orthopaedics & 10 \\
\hline Interns & 19 \\
\hline Total & 100 \\
\hline
\end{tabular}

The clinical disciplines that participated and the number of doctors from each department are set out in Table II. For the analysis, all the surgical disciplines were grouped together. The interns were viewed as a separate group.

Eighty-eight participants admitted to having resuscitation experience, while only 80 had formal resuscitation training, of which only some was still valid (see Table III).

Table III: Resuscitation training of participants

\begin{tabular}{|l|c|c|}
\hline Description & Validation & $\%$ \\
\hline Resuscitation training & & 80 \\
\hline Basic life support & Still valid & 31 \\
\hline Advanced trauma life support & & 49 \\
\hline Advanced cardiac life support & Still valid & 28 \\
\hline Advanced cardiac life support for experienced & & 53 \\
\hline providers & Still valid & 20 \\
\hline Paediatric advanced life support & Still valid & 4 \\
\hline Advanced medical life support & & 27 \\
\hline Other resuscitation training & Still valid & 11 \\
\hline
\end{tabular}

Using the minimum score of $84 \%$, it was disappointing to note that none of the participants demonstrated adequate knowledge (see Table IV). Even after breaking down the score components and having looked at the responses to each question, inadequacies were still apparent (see Tables IV and V).

Table IV: Overall scores

\begin{tabular}{|l|l|l|}
\hline Area & Mean & $95 \%$ CI \\
\hline Part 1: General resuscitation & $31.6 \%$ & $(28.0 ; 35.2)$ \\
\hline Part 2: Adult CPR & $40.6 \%$ & $(37.4 ; 45.6)$ \\
\hline Part 3: Paediatric CPR & $36.6 \%$ & $(37.0 ; 41.6)$ \\
\hline Total score & $35.1 \%$ & $(31.7 ; 38.6)$ \\
\hline
\end{tabular}

$\mathrm{Cl}$ : confidence interval, CPR: cardiopulmonary resuscitation

Table V: Summary of correct responses for each question

\begin{tabular}{|c|c|c|c|}
\hline $\begin{array}{l}\text { Question } \\
\text { number }\end{array}$ & Question content & $\begin{array}{c}\text { Proportion } \\
\text { correct }\end{array}$ & $95 \%$ Cl \\
\hline 1 & $\begin{array}{l}\text { The first thing a healthcare } \\
\text { provider should do if he or she } \\
\text { sees a person collapse }\end{array}$ & $25 \%$ & $(16.4 ; 33.6)$ \\
\hline 2 & $\begin{array}{l}\text { Breathing assessment in a } \\
\text { patient with suspected cardiac } \\
\text { arrest }\end{array}$ & $63 \%$ & $(53.4 ; 72.6)$ \\
\hline 3 & $\begin{array}{l}\text { Pulse check in victims of } \\
\text { cardiac arrest }\end{array}$ & $4 \%$ & $(0.1 ; 7.9)$ \\
\hline 4 & First-aid equipment & $28 \%$ & $(19.0 ; 37.0)$ \\
\hline 5 & Rescue breaths & $13 \%$ & $(6.3 ; 19.7)$ \\
\hline 6 & $\begin{array}{l}\text { Endotracheal intubation during } \\
\text { CPR }\end{array}$ & $70 \%$ & $(60.9 ; 79.1)$ \\
\hline 7 & Ventilation rate & $25 \%$ & $(16.4 ; 33.6)$ \\
\hline 8 & AED & $32 \%$ & $(22.7 ; 41.3)$ \\
\hline 9 & $\begin{array}{l}\text { The shockable cardiac arrest } \\
\text { rhythms }\end{array}$ & $12 \%$ & $(5.5 ; 18.5)$ \\
\hline 10 & $\begin{array}{l}\text { Actions after the AED delivers } \\
\text { a shock }\end{array}$ & $44 \%$ & $(34.1 ; 54.0)$ \\
\hline 11 & $\begin{array}{l}\text { Cardiac compressions during } \\
\text { adult CPR }\end{array}$ & $31 \%$ & $(21.8 ; 40.2)$ \\
\hline 12 & $\begin{array}{l}\text { The rate for external cardiac } \\
\text { compressions during adult } \\
\text { CPR }\end{array}$ & $69 \%$ & $(60.0 ; 78.2)$ \\
\hline 13 & $\begin{array}{l}\text { The rescue breath-chest } \\
\text { compression ratio during two- } \\
\text { rescuer adult CPR }\end{array}$ & $56 \%$ & $(46.1 ; 65.9)$ \\
\hline 14 & $\begin{array}{l}\text { Adult CPR decisions and } \\
\text { actions }\end{array}$ & $29 \%$ & $(20.0 ; 38.0)$ \\
\hline 15 & Defibrillator use in adult CPR & $18 \%$ & $(10.3 ; 25.7)$ \\
\hline 16 & $\begin{array}{l}\text { Rescue breaths during child } \\
\text { CPR }\end{array}$ & $47 \%$ & $(37.0 ; 57.0)$ \\
\hline 17 & $\begin{array}{l}\text { Chest compressions during } \\
\text { neonatal resuscitation }\end{array}$ & $40 \%$ & $(30.2 ; 50.0)$ \\
\hline 18 & $\begin{array}{l}\text { The rescue breath-chest } \\
\text { compression ratio for one- } \\
\text { rescuer infant CPR }\end{array}$ & $32 \%$ & $(22.7 ; 41.3)$ \\
\hline 19 & $\begin{array}{l}\text { The rate for external cardiac } \\
\text { compressions during child } \\
\text { CPR }\end{array}$ & $50 \%$ & $(40.0 ; 60.0)$ \\
\hline 20 & $\begin{array}{l}\text { The energy level for a } \\
\text { shockable cardiac arrest } \\
\text { rhythm in paediatric patients }\end{array}$ & $14 \%$ & $(7.1 ; 20.9)$ \\
\hline
\end{tabular}


Tables VI to IX show the scores of the individual disciplines.

Table VI: Summary statistics for Part 1 (general resuscitation) total score by clinical discipline

\begin{tabular}{l|l|c|c|c|}
\hline Clinical discipline & $\mathbf{n}$ & Mean (SD) & Mean \% & $95 \%$ CI \\
\hline Anaesthesia & 9 & $4.33(1.32)$ & 43.3 & $(33.2 ; 53.5)$ \\
\hline Emergency medicine & 12 & $5.17(1.4)$ & 51.7 & $(42.7 ; 60.6)$ \\
\hline Internal medicine & 12 & $3.42(2.02)$ & 34.2 & $(21.3 ; 47.0)$ \\
\hline Neurology & 7 & $2.00(1.15)$ & 20 & $(9.3 ; 30.7)$ \\
\hline Paediatrics & 9 & $2.22(1.56)$ & 22.2 & $(10.2 ; 34.2)$ \\
\hline Surgery & 32 & $2.53(1.65)$ & 25.3 & $(19.4 ; 31.2)$ \\
\hline $\begin{array}{l}\text { Interns } \\
\text { *: mean out of 10 } \\
\text { Cl: confidence interval, SD: standard deviation }\end{array}$ & 19 & $3.11(1.59)$ & 31.1 & $(23.4 ; 38.7)$ \\
\hline
\end{tabular}

Table VII: Summary statistics for Part 2 (adult cardiopulmonary resuscitation) total score by clinical discipline

\begin{tabular}{|l|c|c|c|c|}
\hline Clinical discipline & $\mathbf{n}$ & Mean (SD)* & Mean \% & $95 \%$ CI \\
\hline Anaesthesia & 9 & $2.44(0.88)$ & 48.8 & $(35.3 ; 62.4)$ \\
\hline Emergency medicine & 12 & $3.33(0.98)$ & 66.7 & $(54.2 ; 79.2)$ \\
\hline Internal medicine & 12 & $2.33(0.98)$ & 46.7 & $(34.2 ; 59.2)$ \\
\hline Neurology & 7 & $1.00(1.29)$ & 20 & $(3.9 ; 43.9)$ \\
\hline Paediatrics & 9 & $0.89(1.05)$ & 17.8 & $(1.6 ; 34.0)$ \\
\hline Surgery & 32 & $1.66(1.04)$ & 33.1 & $(25.7 ; 40.6)$ \\
\hline Interns & 19 & $2.37(1.26)$ & 47.4 & $(35.3 ; 59.5)$ \\
\hline
\end{tabular}

*: mean out of 5

$\mathrm{Cl}$ : confidence interval, SD: standard deviation

Table VIII: Summary statistics for Part 3 (paediatric cardiopulmonary resuscitation) total score by clinical discipline

\begin{tabular}{|l|l|l|l|l|}
\hline Clinical discipline & $\mathbf{n}$ & Mean (SD) & Mean \% & $95 \% \mathbf{C I}$ \\
\hline Anaesthesia & 9 & $3.00(1.00)$ & 60 & $(44.6 ; 75.4)$ \\
\hline Emergency medicine & 12 & $2.50(1.24)$ & 50 & $(34.2 ; 65.8)$ \\
\hline Internal medicine & 12 & $1.58(0.90)$ & 31.7 & $(20.2 ; 43.1)$ \\
\hline Neurology & 7 & $0.86(0.69)$ & 17.1 & $(4.4 ; 29.9)$ \\
\hline Paediatrics & 9 & $2.00(1.50)$ & 40 & $(16.9 ; 63.1)$ \\
\hline Surgery & 32 & $1.50(1.30)$ & 30 & $(20.7 ; 39.3)$ \\
\hline Interns & 19 & $1.84(1.07)$ & 36.8 & $(26.5 ; 47.1)$ \\
\hline $\begin{array}{l}\text { *: mean out of 5 } \\
\text { Cl: confidence interval, SD: standard deviation }\end{array}$ & &
\end{tabular}

Table IX: Summary statistics for the total score by clinical discipline

\begin{tabular}{|l|l|l|l|l|}
\hline Clinical discipline & $\mathrm{n}$ & Mean (SD) & Mean \% & $95 \% \mathrm{Cl}$ \\
\hline Anaesthesia & 9 & $9.78(2.28)$ & 48.9 & $(40.1 ; 57.6)$ \\
\hline Emergency medicine & 12 & $11.00(2.95)$ & 55 & $(45.6 ; 64.4)$ \\
\hline Internal medicine & 12 & $7.33(2.67)$ & 36.7 & $(28.2 ; 45.2)$ \\
\hline Neurology & 7 & $3.86(2.54)$ & 19.3 & $(7.5 ; 31.1)$ \\
\hline Paediatrics & 9 & $5.11(3.06)$ & 25.6 & $(13.8 ; 37.3)$ \\
\hline Surgery & 32 & $5.69(3.07)$ & 28.4 & $(22.9 ; 34)$ \\
\hline Interns & 19 & $7.32(2.87)$ & 36.6 & $(29.7 ; 43.5)$ \\
\hline $\begin{array}{l}\text { *: mean out of 20 } \\
\text { Cl: confidence interval, SD: standard deviation }\end{array}$ & &
\end{tabular}

\section{Discussion}

The results of this study, which indicate a significant lack in the retention of knowledge of CPR, were surprising. Considering that the majority of participants were senior doctors in their discipline (see Figure 2) and that $80 \%$ of them had some resuscitation training (see Table III), and more importantly that $88 \%$ admitted to having resuscitation experience, better scores were expected. These results are similar to studies that indicated poor retention of both knowledge and skills in this area. ${ }^{19-22}$ Brown et al demonstrated that accurate knowledge of guidelines was associated with increased odds of correct performance of some aspects of CPR. This raises considerable concern about the effectiveness of CPR that is performed by clinicians. $^{23}$

Emergency Medicine had the best total score of 55\% (95\% Cl: 45.6; 64.4). Emergency Medicine also had the best score in all the parts, except Part 3 (paediatric CPR), in which Anaesthesia scored the highest, with a mean of $60 \%$ (95\% $\mathrm{Cl}: 44.6 ; 75.4)$. This may indicate the greater emphasis that is placed on CPR skills in disciplines such as Emergency Medicine and Anaesthesia.

However, the $\mathrm{Cl}$ in some groups overlapped. The difference might not be statistically significant. For this reason, in order to draw valid conclusions about differences in the obtained results from the clinical disciplines, a larger sample size is needed and might be motivation for further research.

The spread of medical staff who were surveyed reflects the general pattern of medical staff in the hospital. However, this is a variable and may change due to the intake of inexperienced registrars and the departure of experienced registrars. It might also alter during clinical exams.

Notably, the interns scored comparatively well with the more senior doctors in the hospital, coming fourth overall, with a total score of $36.6 \%$ (95\% Cl: $29.7 ; 43.5)$. This might indicate that they had retained some CPR training and skills from their undergraduate studies which they had completed more recently than the other participants.

With regard to the individual questions, Question 3 concerned aspects of checking the pulse. This had the lowest score. Only $4 \%(95 \% \mathrm{Cl}: 0.1 ; 7.9)$ answered it correctly (see Table V). This confirms that pulse checks are often carried out incorrectly by trained healthcare workers and are no longer recommended for lay rescuers. ${ }^{6,38}$

It is interesting to note that in response to Question 4, regarding which first-aid equipment should be prioritised, 68 participants answered that airway and oxygen equipment should take priority. This might suggest that participants were unaware of the new guidelines that de-emphasise airway and ventilation early on in CPR. ${ }^{16,17}$

The main finding of this study was that all doctors who participated performed poorly. The mean total score was $35.1 \%$ (95\% Cl: 31.7 ; 38.6). This score is far below what was expected, namely $84 \%$. 
It appears that the existing training structures for CPR are inadequate for doctors at this facility.

\section{Limitations}

This study was limited to the doctors who attended the respected departmental meetings and those who consented until a sample size of 100 was reached.

The study was conducted by a single investigator using a questionnaire that was based on the course content of the AHA BLS course and validated by an experienced AHA BLS instructor.

There was a period in which data was not collected due to university examinations.

The interns who participated in October 2010 might have had more experience than those who participated in January 2011 (the beginning of intern rotations). This might have impacted on the study.

\section{Recommendations}

Existing CPR training structures need to be revised in order to equip doctors with better CPR knowledge.

It is recommended that programme directors of clinical specialties place more emphasis on CPR in their training programmes and syllabi.

The development of appropriate, accessible, inexpensive CPR training programmes is recommended.

A similar study, using a larger sample size, is needed in order to make valid conclusions about the differences in the obtained results from the clinical disciplines.

\section{Conclusion}

Participants' knowledge of resuscitation was disappointingly poor. Considering that the majority of participants were senior doctors in their discipline, and that a high percentage had some resuscitation training and resuscitation experience, better scores were expected. This raises considerable concern about the effectiveness of CPR that is performed by some clinicians. The introduction of routine and periodic CPR training programmes should be mandatory for all clinical specialties and should be integrated as part of the existing syllabus. This should include all categories of staff, including registrars, medical officers, interns and nurses. It should be a requirement that senior registrars and senior medical officers have valid training certificates in CPR. They should set an example to their junior colleagues. At some point in their careers, medical staff will be confronted by a patient in need of resuscitation, so adequate CPR and BLS knowledge and skills are imperative to patient outcome and survival. CPR saves lives. This study highlights the need for adequate training of clinicians in the skill of resuscitation and the importance of developing appropriate CPR training programmes that are accessible, innovative and inexpensive. Ultimately, better-trained rescuers mean more lives saved.

\section{Acknowledgements}

We acknowledge the support of all the clinical departments that took part in the study. We are thankful to Prof Piet Becker of the Medical Research Council for his valuable comments and his guidance regarding the statistical analysis.

\section{References}

1. American Heart Association. BLS for healthcare providers. Dallas: AHA; 2006.

2. Adult basic life support. Resuscitation Council UK [homepage on the Internet]. c2011. Available from: http://www.resus.org.uk/pages/bls.pdf

3. Kuller L, Lilienfeld A, Fisher R. An epidemiological study of sudden and unexpected deaths in adults. Medicine (Baltimore). 1967;46(4):341.

4. Cummins RO, Chamberlain DA, Abramson NS, et al. Recommended guidelines for uniform reporting of data from out-of-hospital cardiac arrest: the Utstein style. Circulation. 1991;84(2):960-975.

5. Marx JA, Hockberger RS, Walls RM, et al. In: Adams JG, Barsan WG, Biros MH, et al, editors. Rosen's emergency medicine concepts and clinical practice, $6^{\text {th }}$ ed. Philadelphia: Mosby Elsevier; 2005

6. American Heart Association. ACLS resource text for instructors and experienced providers. Dallas: AHA; 2008

7. Johnson A. An account of some societies at Amsterdam and Hamburg for the recovery of drowned persons. London; 1773.

8. Baskett PJF. Obituary: Peter J Safar. Resuscitation. 2003;59(1):3-5.

9. Zoll PM, Linenthal AJ, Gibson W, et al. Termination of ventricular fibrillation in man by externally applied electric countershock. N Engl J Med. 1956;254(16):727.

10. CPR statistics. American Heart Association [homepage on the Internet]. c2011. Available from: http://www.heart.org/HEARTORG/CPRAndECC/WhatisCPR/ CPRFactsandStats/CPR-Statistics_UCM_307542_Article.jsp

11. Brindley PG, Markland DM, Kutsogiannis DJ. Predictors of survival following inhospital adult cardiopulmonary resuscitation. CMAJ. 2002;174(4):343.

12. Resuscitation Council (UK) comments on compression-only CPR study published in The Lancet 17 March 2007. Resuscitation council UK. [homepage on the Internet]. c2011. Available from: http://web.archive.org/web/20070612203024/ http://www.resus.org.uk/pages/compCPRs.htm

13. International Liaison Committee on Resuscitation. International consensus on cardiopulmonary resuscitation (CPR) and emergency cardiovascular care (ECC) science with treatment recommendations. Circulation. 2005;112(Suppl 22):III1:III-136, B1-B18

14. Ewy, Gordon A. A new cardiopulmonary resuscitation. Circulation. 2004;111(16):2134-2142.

15. SOS-KANTO Study Group. Cardiopulmonary resuscitation by bystanders with chest compression only (SOS-KANTO): an observational study. Lancet. 2007;69(9565):920-926.

16. Sayre MR, Berg RA, Cave DM, et al. Hands-only (compression-only) cardiopulmonary resuscitation: a call to action for bystander response to adults who experience out-of-hospital sudden cardiac arrest: a science advisory for the public from the American Heart Association Emergency Cardiovascular Care Committee. Circulation. 2008;117(16):2162-2167.

17. Hazinski MF, Nolan JP, Billi JE, et al. 2010 International consensus on cardiopulmonary resuscitation and emergency cardiovascular care science with treatment recommendations. Circulation 2010;122(Suppl 2):250-581.

18. Fox CS, Evans JC, Larson MG, et al. Temporal trends in coronary heart disease mortality and sudden cardiac death from 1950 to 1999: the Framingham Heart Study. Circulation. 2004;110(5):522-527.

19. Desalu I, Kushimo O, Akinlaja O. Adherence to CPR guidelines during perioperative 
cardiac arrest in a developing country. Resuscitation. 2006;69(3):517-520.

20. Solagberu BA. Knowledge and practice of cardiopulmonary resuscitation among Nigerian doctors. Niger J Surg Res. 2002;4(1):12-21.

21. David J, Prior-Willeard PFS. Resuscitation skills of MRCP candidates. BMJ. 1993;306(6892):1578-1579.

22. Ragavan S, Schneider H, Kloeck WGJ. Basic resuscitation: knowledge and skills of full-time medical practitioners at public hospitals in Northern Province. S Afr Med J. 2000;90(5):504-508.

23. Brown TB, Dias JA, Devashish S, et al. Relationship between knowledge of cardiopulmonary resuscitation guidelines and performance. Resuscitation. 2006;69(2):253-261.

24. Einspruch EL, Lynch B, Aufderheide TP, et al. Retention of CPR skills learned in a traditional AHA Heartsaver course versus 30-min video self-training: A controlled randomized study. Resuscitation. 2007;74(3):476-486.

25. Braslow A. An evaluation of the knowledge and practices of basic cardiac life support instructors (dissertation). Champaign, Illinois: University of Illinois; 1985.

26. Kaye W, Rallis S, Mancini ME, et al. The problem of poor retention of cardiopulmonary resuscitation skills may lie with the instructor, not the learner or the curriculum. Resuscitation. 1991;21(1):67-87.

27. Brennan RT, Braslow A. Skill mastery in cardiopulmonary resuscitation training classes. Am J Emerg Med. 1995;13(5):505-508.

28. Hunt EA, et al. Resuscitation education: narrowing the gap between evidencebased resuscitation guidelines and performance using best educational practices. Pediatr Clin North Am. 2008;55(4):1025-1050.

29. Jabbour M, Osmond MH, Klassen TP. Life support courses: are they effective? Ann Emerg Med. 1996;28(6):690-698.
30. Wynne G, Marteau T, Evans TR. Instructors: a weak link in resuscitation training. J R Coll Physicians Lond. 1992;26(4):372-373.

31. Castle N, Garton H, Kenward G, et al. Confidence vs. competence: basic life support of health professionals. Br J Nurs. 2007;16(11):664-666.

32. Waisman Y, Amir L, Mimouni M. Does the pediatric advanced life support course improve knowledge of pediatric resuscitation? Pediatr Emerg Care. 2002;18(3):168-170.

33. Lowenstein SR, Sabyan EM, Lassen CF, Kern DC. Benefits of training physicians in advanced cardiac life support. Chest. 1986;89(4);512-516.

34. Curry L, Gass D. Effects of training in cardiopulmonary resuscitation on competence and patient outcome. J Can Med Assoc. 1987;137(6):491-496.

35. Menezes BF, Morgan R. Attitudes of doctors in training to cardiopulmonary resuscitation. Clin Med. 2008;8(2):149-151.

36. Berden HJ, Willems FF, Hendrick JP, et al. How frequently should basic cardiopulmonary resuscitation training be repeated to maintain adequate skills? BMJ. 1993;306(6892):1576-1577.

37. Faculty of Health Sciences Yearbook 2011. University of Pretoria [homepage on the Internet]. c2011. Available from: http://web.up.ac.za/sitefiles/file/2011\%20 yearbooks/Health\%20Sciences\%202011.pdf

38. Hazinski MF, Nolan JP, Billi JE, et al. Part 1: Executive Summary 2010 International Consensus on Cardiopulmonary Resuscitation and Emergency Cardiovascular Care Science With Treatment Recommendations. Circulation. 2010;122[suppl 2]:S250-S275 